\title{
Time trends and seasonal variation in hospital admissions for childhood asthma in the Athens region of Greece: $1978-88$
}

\author{
K Priftis, J Anagnostakis, E Harokopos, I Orfanou, M Petraki, P Saxoni-Papageorgiou
}

Allergy Department, Penteli Children's Hospital, Palea Penteli 152 36, Greece K Priftis

$\mathrm{J}$ Anagnostakis

1st Paediatric

Department,

University of Athens,

"Agia Sophia"

Children's Hospital,

Greece

E Harokopos

I Orfanou

2nd Paediatric

Department,

University of Athens,

"P \& A Kyriakou"

Children's Hospital,

Greece

M Petraki

P Saxoni-Papageorgiou

Reprint requests to:

Dr K Priftis

Received 2 February 1993

Returned to authors

30 March 1993

Revised version received

20 July 1993

Accepted 11 August 1993

\begin{abstract}
Background-The aim of the study was to determine the trend and seasonal variation in hospital admissions for childhood asthma in the Athens region of Greece.

Methods-Data were obtained from hospital registries of the three main children's hospitals in Athens between 1978 and 1988. Children admitted with the diagnosis of asthma, asthmatic bronchitis, or wheezy bronchitis were included. The data were expressed as admission rates per 100000 of the same aged population.

Results-There were 9795 admissions for asthma over the 11 years and the admission rate rose by $294 \%$. Admissions among those aged $0-4$ and 5-14 rose by $272 \%$ and $379 \%$ respectively. Monthly admissions showed a pronounced seasonal variation, rising during the cold damp period in the $0-4$ age group, but peaking around May in the 5-14 age group.

Conclusions-These findings suggest that hospital admissions due to asthma in the Athens region have increased considerably since 1978, and that clear cut seasonal variations exist which are specific to age.
\end{abstract}

(Thorax 1993;48:1168-1169)

Hospital admission rates for childhood asthma have been increasing over the past

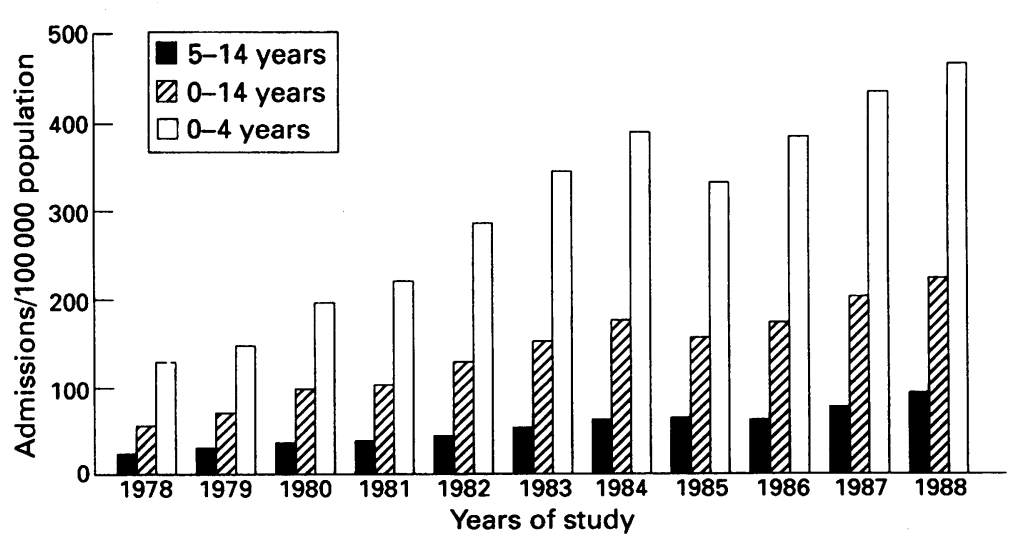

Figure 1 Trends in asthma admissions for children aged 0-14 years, 0-4 years, and 5-14 years in the Athens region during 1978-88. two decades in several countries. ${ }^{1}$ This reflects either a change in prevalence and morbidity, or modification of the manage- $\vec{x}$ ment of childhood asthma, or both. In addi- $\stackrel{\infty}{\infty}$ tion, seasonal variation in asthma admissions can be used as an indicator of trigger factors provoking asthma attacks in a particular area. $^{2}$

The aim of this study was to determine the time trends and seasonal variation in hospital admissions for childhood asthma in the Athens region of Greece during an 11 year period between 1978 and 1988.

\section{Methods}

Data were obtained from hospital registries of the three main children's hospitals of Athens, covering $80 \%$ of the paediatric beds of the region, for the $1978-88$ period.

Children admitted with a diagnosis of asthma, asthmatic bronchitis, or wheezy bronchitis living in the region were included. Dates of birth at admission were obtained. The children were classified into two age groups: $0-4$ and 5-14 years. Those admitted with a diagnosis of acute bronchiolitis were excluded.

The data were expressed as admission rates per $10^{5}$ population aged the same as the two $\delta$ groups studied. The population estimation 3 aged 0-14 years for each year of the study 9 period was based upon the 1981 census.

Monthly hospital admissions for asthma during each year were converted into percent- on age of mean monthly admissions for asthma during that year. The resulting values were averaged for each month over the whole period studied.

Trends were tested by $\chi^{2}$ analysis.

\section{Results}

During the 1978-88 period 9795 children were admitted to hospital with asthma; 7484 $(76.4 \%)$ were $0-4$ years of age and 2311 (23.6\%) were aged 5-14.

The trend in admissions for asthma for $\delta$ children aged 0-14, after adjusting for the missing $20 \%$ of paediatric beds in the region, 윽 are shown in fig 1 . In 1978 the admission rate was 56 per $10^{5}$ population aged 0-14 years, but in 1988 the rate was 222 per $10^{5}$, an increase of $294 \%\left(\chi^{2}\right.$ for trend, $\left.p<0.001\right)$ with a mean annual rate of increase of $11 \cdot 8 \%$. 


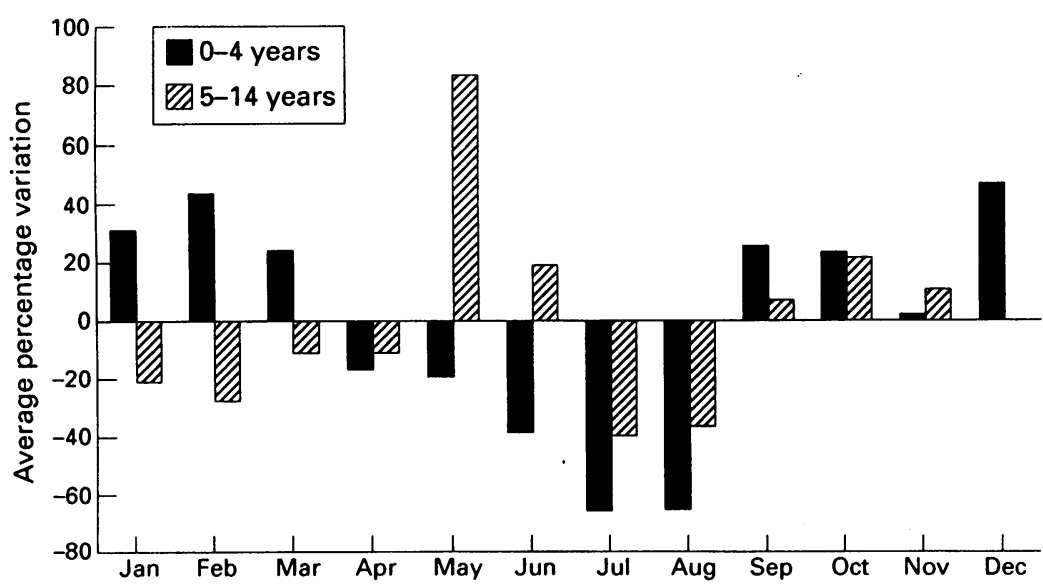

Figure 2 Monthly variation in asthma admissions for children aged 0-4 and 5-14 years in Athens, Greece. were unable to test any hypothesis as to why the childhood asthma admission rate has shown such an increase.

In contrast to the study by Anderson, ${ }^{4}$ we found that admissions among the 5-14 age group showed a more rapid increase in trend than that among the $0-4$ year group. There is no obvious explanation for this.

The two age groups had a quite different pattern of seasonal variation of admission rate. The increased admission rate during the cold damp period in the preschool age group correlated best with the increased incidence of viral infections at that time of the year. ${ }^{5}$ The older children showed an increased admission rate in late spring, early summer and autumn, with a very strong peak in May. As sensitisation to inhaled allergens usually starts after the age of 5 years, the seasonal pattern observed in children aged $5-14$ is probably due to the pollen count and less to house dust mites. House dust mites require conditions of high temperature and relative humidity ${ }^{6}$ which are prevalent during the same period in Greece. However, indoor mite antigen levels are also high in the Athens region during the winter months (P. SaxoniPapageorgiou, unpublished data). Increased airborne pollen concentrations are recorded for olive, grasses and Parietaria pollens, which are the commonest sensitising airborne pollen allergens in Greece..$^{7-9}$ Furthermore, the trough in the first months of the year makes viral infections a less likely provoking factor in the older age group.

These findings suggest that the annual admission rates due to childhood asthma in the Athens region have shown a fourfold increase since 1978. A different seasonal variation in admissions between the two age groups was detected, indicating the difference in environmental factors implicated in provoking asthma attacks in preschool children, and those of school age.

1 Mitchell EA. International trends in hospital admission rates for asthma. Arch Dis Child 1985;60:376-8.

2 Khot A, Burn R, Evans N, Lenney C, Lenny W. Seasona variation and time trends in childhood asthma in England and Wales 1975-81. BMF 1984;289:235-7.

3 Priftis K, Frimas K, Misiris S, Ramos T, Filoxenidi A Anagnostakis J. Increasing prevalence of childhood asthma in Greece. Allergy 1992;47(Suppl 12):37s.

4 Anderson HR. Increase in hospital admissions for childhood asthma: trends in referral, severity, and readmissions from 1970 to 1985 in a health region of the United Kingdom. Thorax 1989;44:614-9.

5 Priftis K, Spyrou N, Kanellopoulou M, Filoxenidi A Korra S, Karakatsani Z, et al. Viral pathogens with acute lower respiratory tract infection in young children in Greece: 1988-1991. Eur Respir ff 1992;5(Suppl 15): 227s.

6 Arlian LG. Humidity as a factor regulating feeding and balance of the house dust mites Dermatophagoides farinae and Dermatophagoides pteronyssinus. $\mathcal{F}$ Med Entomol 1977; 14:484-8.

7 Apostolou E, Yanitsaros A. Atmospheric pollen in the area of Athens. Acta Allergol 1977;32:109-18.

8 Giulekas D, Chatzigeorgiou G, Spieksma F. Allergenic pollen and pollinosis in Northern Greece. In: Amato D, ed. Allergenic pollen and pollinosis in Europe. Oxford: Blackwell, 1991;167-71.

9 Priftis K, Ziya M, Mathioudakis G, Ilia M, Grypari M, Anagnostakis J, et al. Sensitization of asthmatic children to common environmental allergens according to their residence. F Asthma 1993;30:445-50. management and admissions criteria might be responsible for our observations, but there are no data to support this. Consequently, we 